\title{
APLIKASI SKYLIGHT DAN JENDELA UNTUK OPTIMALISASI PENCAHAYAAN ALAMI PADA RUMAH TINGGAL
}

\author{
Yunita Ardianti Sabtalistia \\ Dosen Prodi S1 Arsitektur, Fak.Teknik, Universitas Tarumanagara, Jakarta \\ e-mail: yunitas@ft.untar.ac.id \\ Sintia Dewi Wulanningrum \\ Dosen Prodi S1 Arsitektur, Fak.Teknik, Universitas Tarumanagara, Jakarta \\ e-mail: sintiaw@ft.untar.ac.id
}

\begin{abstract}
ABSTRAK
Bukaan yang ada di rumah, seperti: jendela, ventilasi, dan skylight bisa dioptimalkan kinerjanya sehingga pemakaian lampu bisa dikurangi atau bahkan tidak digunakan sama sekali dari pagi sampai sore hari. Ruanganruangan yang paling banyak digunakan dari pagi sampai sore hari adalah ruang kerja, dapur, dan ruang makan. Berdasarkan permasalahan tersebut maka penelitian ini bertujuan mengoptimalkan skylight dan jendela agar ruang kerja, ruang makan, dan dapur pada rumah tinggal mempunyai pencahayaan alami yang optimal. Sampel penelitian yang digunakan adalah rumah tipe 27/60 yang menghadap ke arah barat daya. Rumah tersebut mempunyai bukaan, seperti: jendela, ventilasi, dan skylight. Metode yang digunakan adalah metode eksperimen dengan menggunakan simulasi Autodesk Ecotect Analysis 2011. Ada 2 solusi yang direkomendasikan untuk diaplikasikan agar ruang kerja, ruang makan, dan dapur mendekati nilai SNI 6197:2011. Solusi pertama diterapkan pada saat kegiatan kerja dan makan sedangkan solusi kedua diterapkan pada saat kegiatan memasak. Solusi yang pertama dengan menutup korden sebesar $50 \%$ pada jendela ruang kerja dan ruang tidur depan, menutup korden sebesar $100 \%$ pada jendela belakang, pemberian horizontal overhang pada jendela belakang, dan mengurangi luas skylight sebesar 50\%. Solusi yang kedua dengan membuka daun pintu depan dan daun jendela belakang.
\end{abstract}

\section{Kata kunci : Jendela, Pencahayaan Alami, Rumah Tinggal, Skylight}

\section{ABSTRACT}

The performance of existing openings in the house, such as windows, vents and skylights, can be optimized so that the use of lights can be reduced or even not used at all from morning to evening. The most used rooms from morning to evening are the den, kitchen and dining room. Based on these problems, this study aims to optimize the skylights and windows so that the workspace, dining room, and kitchen in the residence have optimal natural lighting. The research sample used is the house type 27/60 facing the southwest. The house has openings, such as: windows, vents, and skylights. The method used is an experimental method using Autodesk Ecotect Analysis 2011 simulation. There are 2 recommended solutions to be applied 
so that the workspace, dining room, and kitchen approach the SNI 6197: 2011 value. The first solution is applied during work and eating activities, while the second solution is applied during cooking activities. The first solution is to close the curtains by $50 \%$ on the workspace and front bedroom windows, close the curtains by $100 \%$ on the rear windows, provide a horizontal overhang on the rear windows, and reduce the skylight area by 50\%. The second solution is to open the front door and rear shutters.

\section{Keywords: Window, Natural Ventilation, House, Skylight}

\section{PENDAHULUAN}

Saat ini kita mengalami masa pandemi Corona dimana hampir sebagian besar karyawan bekerja di rumah (Work From Home/WFH). Pada pagi sampai sore hari, pencahayaan alami di rumah tinggal dapat dimanfaatkan untuk bekerja sehingga tidak perlu menggunakan lampu.

Salah satu penelitian yang berfokus pada pencahayaan alami rumah tinggal adalah penelitian lbayasid dkk, 2020. Studi kasus yang digunakan adalah rumah tinggal tipe $27 \mathrm{~m}^{2}$ dengan orientasi bangunan menghadap barat. Berbagai model bukaan dieksperimen untuk mengetahui model bukaan mana yang paling mampu memberikan pencahayaan alami yang optimal. Hasilnya membuktikan bahwa model bukaan $10 \%$ di sisi barat, $10 \%$ bukaan atap, dan 50\% bukaan timur paling mampu memberikan daylighting level paling optimal, yaitu sebesar 998,83 Lux pada kondisi clear sky dan 849 lux pada overcast sky (lbayasid dkk, 2020:101).

Berdasarkan standard SNI 6197:2011 menyatakan bahwa kebutuhan pencahayaan untuk rumah tinggal berkisar antara 250-300 lux untuk ruang kerja, dapur, dan ruang makan. Oleh karena adanya WFH (Work From Home), ruang kerja menjadi ruang yang paling banyak kita tempati sepanjang hari. Kegiatan memasak selama masa pandemi ini juga menjadi kegiatan yang banyak dilakukan karena untuk mempertahankan daya tahan tubuh perlu makanan yang sehat dan bergizi, serta higienis. Para ibu cenderung memasak sendiri agar makan yang disajikan bisa lebih terjamin kebersihannya. Oleh karena itu dapur dan ruang makan perlu diperhatikan level pencahayaannya agar kegiatan memasak dan makan bersama keluarga dapat berjalan dengan baik dan tanpa menggunakan lampu.

Bukaan pada rumah tinggal dapat didapatkan dari samping, seperti: jendela dan ventilasi. Bukaan dari atas bisa didapatkan dari skylight. Penelitian ini bertujuan mengoptimalkan skylight dan jendela agar ruang kerja, ruang makan, dan dapur pada rumah tinggal memberikan pencahayaan alami yang mendekati SNI 6197:2011. 


\section{TINJAUAN PUSTAKA}

Skylight bertujuan untuk memasukkan cahaya matahari dari atas bangunan. Skylight banyak diterapkan di atrium mall. Salah satu atrium mall yang menggunakan skylight adalah Lenmarc Mall yang ada di Surabaya. Banyak pengunjung mall Lenmarc Mall yang mengeluhkan mengalami kesilauan pada saat di atrium. Oleh karena itu pihak Lenmarc Mall menambahkan polikarbonat putih susu pada skylight atrium tersebut. Namun, penambahan polikarbonat tersebut membuat atrium menjadi gelap. Dari permasalahan tersebut, Hartono dkk,2019 menguji coba perbaikan skylight dengan 3 cara, yaitu: pemberian kaca film $20 \%$, kaca film $40 \%$, dan tambahan saringan matahari (Hartono dkk, 2019:608). Hasilnya membuktikan bahwa penambahan kaca film 40 \% paling mampu memenuhi Daylight Factor (DF) minimal dan cahaya yang dihasilkan cenderung tidak menyilaukan.

Optimalisasi pencahayaan alami dapat dilakukan dengan strategi memperbesar Window Wall Ratio (WWR), selubung ganda (double facade), dan shading device. Sebuah penelitian dengan studi kasus ruko di Lhokseumawe telah membuktikan bahwa dengan meningkatkan nilai WWR, penggunaan daylight shaft, skylight, selubung ganda, dan shading device mampu meningkatkan nilai Useful Daylight Illuminance (UDI) yang sebelumnya $76 \%$ gelap ( $<100$ Lux) menjadi $73 \%$ optimal (antara 100-2000 Lux) (Atthaillah dkk, 2019). 
Shading Device yang diaplikasikan pada jendela bertujuan memberikan pembayangan agar bangunan menjadi tidak terlalu panas. Selain itu juga merupakan penghalang agar sebagian besar cahaya yang masuk ke dalam ruangan bukan cahaya langsung tetapi cahaya pantulan sehingga tidak menyilaukan atau tidak menimbulkan glare. Penelitian Sabtalistia, 2017 menguji beberapa model shading device, seperti: eggcrate, horizontal overhang, horizontal louver, vertical louver, dan light shelf. Hasilnya membuktikan bahwa horizontal overhang dengan panjang 1,2 meter mampu memberikan daylighting level rata-rata dan uniformity ratio paling optimal.

\section{METODE PENELITIAN}

Parameter yang dapat digunakan untuk mengukur kualitas pencahayaan alami pada penelitian ini adalah Daylighting Level yang mempunyai satuan lux. Daylighting level menjadi optimal jika nilainya sesuai dengan standard SNI 6197:2011.

Metode penelitian yang digunakan adalah metode eksperimen. Alat simulasi yang digunakan adalah Autodesk Ecotect Analysis 2011. Metode eksperimen lebih berfokus pada hubungan sebab dan akibat (Groat dkk, 2002). Dengan melakukan eksperimen pengaturan buka tutup pintu, jendela, dan korden, pengaturan luasan skylight, serta penambahan shading device dapat mempengaruhi daylighting level yang masuk ke dalam rumah. Pengaturan buka tutup pintu, jendela, korden, pengaturan luasan skylight, dan penambahan shading device menjadi penyebab terjadinya perubahan daylighting level. Daylighting level menjadi akibat dari dilakukannya eksperimen tersebut.

Sampel penelitian yang digunakan adalah sebuah rumah tinggal yang berlokasi di Perumahan Forest Hill, Cluster the Village, Acero 2, Blok H11, No.2, Parung Panjang, Bogor, Jawa Barat. Rumah bertipe 27/60 tersebut menghadap ke arah barat daya sehingga pada saat pagi hari cenderung teduh di bagian depan rumah dan cenderung terang di bagian belakang rumah. Rumah tersebut berada di hook sehingga sisi kiri dan sisi belakang bangunan merupakan area hijau.

Pada bagian depan rumah tampak ada 2 jendela (Gambar 1). Ventilasi ada di atas jendela. Ventilasi tersebut ditutup oleh kaca sehingga hanya memasukkan cahaya matahari dan tidak memasukkan angin. Bagian depan rumah menggunakan shading device dengan bahan U-PVC yang cukup panjang sehingga teras rumah terbayangi cukup baik. Tidak ada tanaman yang tinggi dan perabot yang menghalangi masuknya cahaya dari depan (Gambar 1). Pada bagian samping kiri rumah tidak ada bukaan sama sekali sehingga tidak ada cahaya yang masuk dari samping kiri (Gambar 2 kiri). Tinggi lantai ke plafon adalah 3 meter. Pada bagian belakang ada 1 jendela dan skylight untuk ruang jemur dan taman dalam (Gambar 2 kanan dan 3). Dua jendela yang ada di depan mempunyai ukuran yang sama, yaitu: $63,8 \mathrm{x}$

PAWON: Jurnal Arsitektur, Nomor 01 Volume V, Januari-Juni Tahun 2021, ISSN 2597-7636 
$125 \mathrm{~cm}$. Jendela belakang mempunyai ukuran $40 \times 100 \mathrm{~cm}$. Skylight mempunyai ukuran $167,9 \times 161 \mathrm{~cm}$. Pintu depan mempunyai ukuran $94,5 \times$ $215 \mathrm{~cm}$.

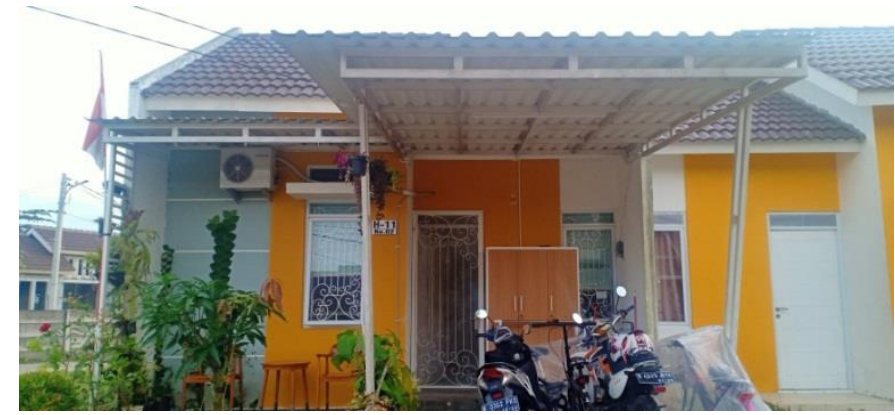

Gambar. 1

Tampak Depan Sampel Penelitian Sumber: Dokumentasi, Desember 2020
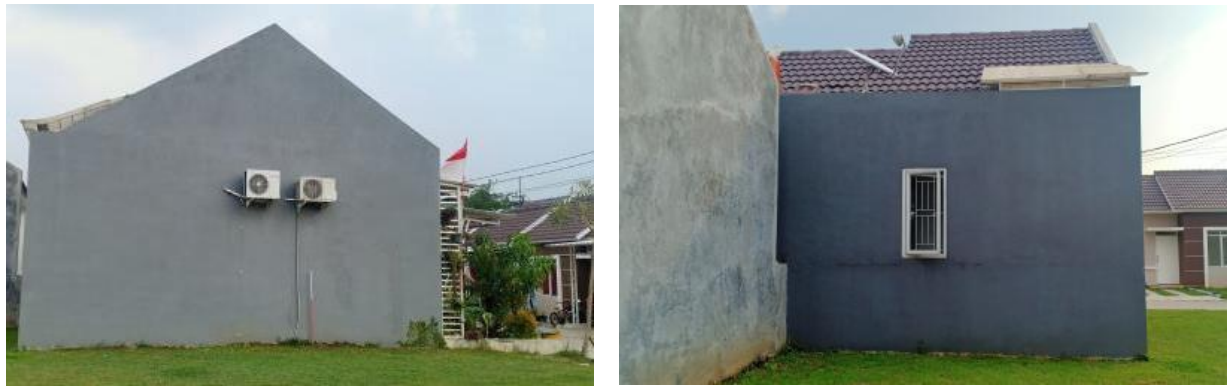

Gambar. 2

Tampak Samping Kiri dan Tampak Belakang Sampel Penelitian

Sumber: Dokumentasi, Desember 2020

Susunan ruang dari depan ke belakang terdiri dari teras, ruang kerja/ruang keluarga, ruang tidur 1 , ruang tidur 2 , KM/WC, dapur, ruang makan, dan taman dalam (innercourt) (Gambar 4). Taman dalam tersebut juga berfungsi sebagai jemuran sehingga pada bagian atas dipasang atap polycarbonat agar sinar matahari bisa masuk. Atap polycarbonat tersebut berfungsi sebagai skylight. Ruang makan dan dapur mendapatkan banyak sumber cahaya alami dari skylight dan jendela belakang. Ruang kerja dan ruang tidur mendapatkan sumber cahaya dari jendela depan. Perabot yang ada di depan jendela ruang kerja dan ruang tidur 1 tidak menghalangi cahaya masuk ke dalam ruangan karena tinggi perabot tidak melebihi tinggi jendela (Gambar 4). Adapun perabot tersebut adalah meja dan sofa. 

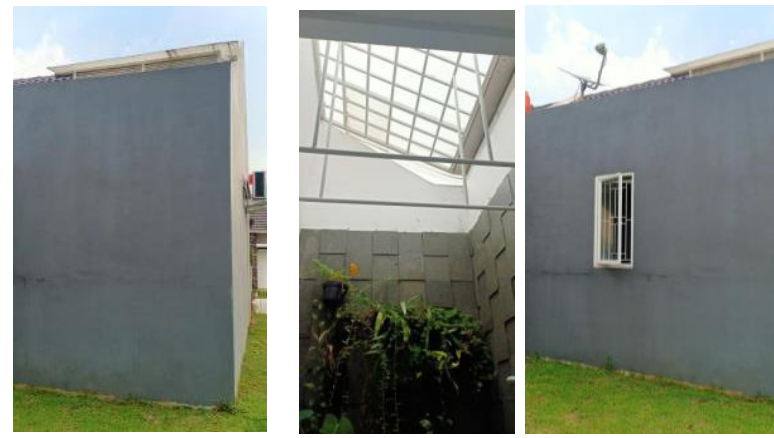

Gambar. 3

Skylight dan Jendela Belakang Sampel Penelitian Sumber: Dokumentasi, Desember 2020

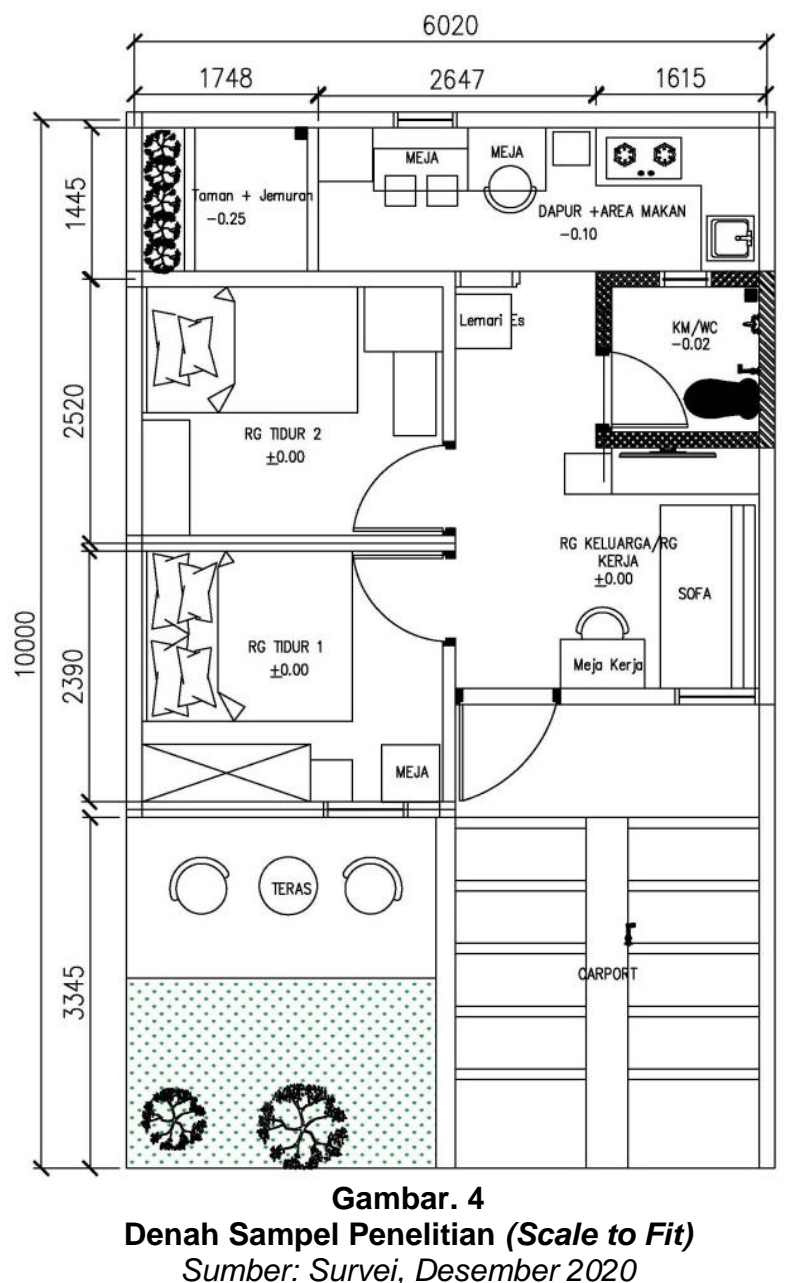

Sumber: Survei, Desember 2020 


\section{HASIL DAN PEMBAHASAN}

\subsection{KONDISI EKSISTING}

Sampel penelitian dimodelkan dengan Ecotect sesuai dengan kondisi di lapangan. Gambar 5 menunjukkan model rumah dari depan dan belakang. Setelah dimodelkan selanjutkan dilakukan simulasi perhitungan Daylighting Level. Kondisi eksisting mensimulasikan daylighting level pada saat semua jendela dibuka (tidak tertutup korden) dan pintu ruang kerja ditutup. Gambar 6 menunjukkan daylighting level pada seluruh ruangan. Pada area skylight dan area sekitar jendela mempunyai daylghting level lebih tinggi. Daylighting level pada ruang kerja, ruang tidur 1 , dan ruang makan cenderung lebih terang jika dibandingkan SNI terutama pada ruang makan (Tabel 1 dan Gambar 7 kiri). Namun, sebaliknya pada dapur cenderung sedikit kurang terang jika dibandingkan SNI (Gambar 7 kanan).
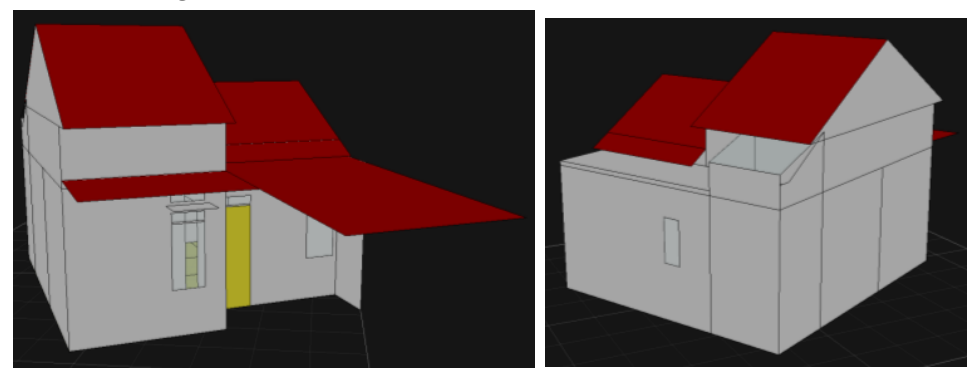

Gambar. 5

Modelling Sampel Penelitian

Sumber: Ecotect, Desember 2020

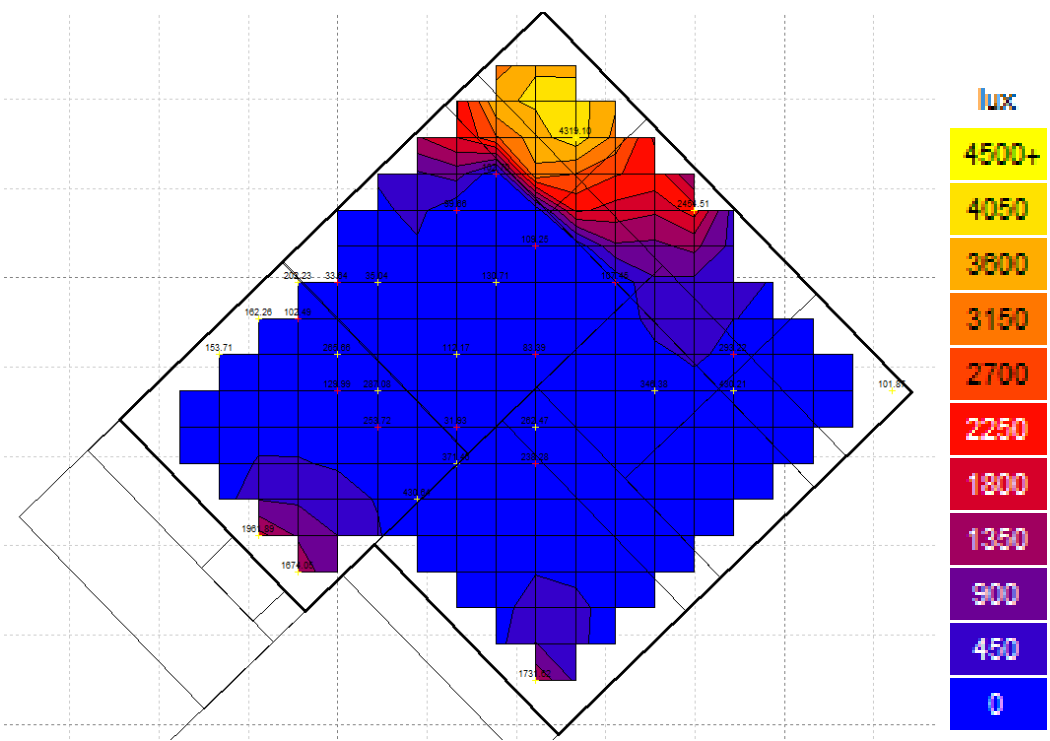

Gambar. 6

Daylighting Level pada Kondisi Eksisting

Sumber: Ecotect, Desember 2020, pukul 12.00 WIB

PAWON: Jurnal Arsitektur, Nomor 01 Volume V, Januari-Juni Tahun 2021, ISSN 2597-7636 
Tabel 1.

Nilai Daylighting Level (Lux) pada Kondisi Eksisting

\begin{tabular}{|l|c|c|c|c|c|}
\hline & Skylight & Ruang Kerja & Ruang Tidur 1 & $\begin{array}{c}\text { Ruang } \\
\text { Makan }\end{array}$ & Dapur \\
\hline Daylighting Level Minimal & 2889 & 127 & 90 & 814 & 51 \\
\hline Daylighting Level Maksimal & 4719 & 1798 & 2478 & 2381 & 533 \\
\hline Daylighting Level Rata-rata & 3519 & $\mathbf{3 4 3}$ & $\mathbf{3 9 3}$ & $\mathbf{1 4 3 2}$ & $\mathbf{2 3 5}$ \\
\hline Nilai SNI 6197:2011 & - & $\mathbf{3 0 0}$ & $\mathbf{2 5 0}$ & $\mathbf{2 5 0}$ & $\mathbf{2 5 0}$ \\
\hline $\begin{array}{l}\text { Selisih Daylighting Level } \\
\text { Rata-rata dengan SNI } \\
\text { 6197:2011 }\end{array}$ & - & $\mathbf{4 3}$ & $\mathbf{1 4 3}$ & $\mathbf{1 1 8 2}$ & $\mathbf{1 5}$ \\
\hline
\end{tabular}

Sumber: Ecotect, Desember 2020, pukul 12.00 WIB
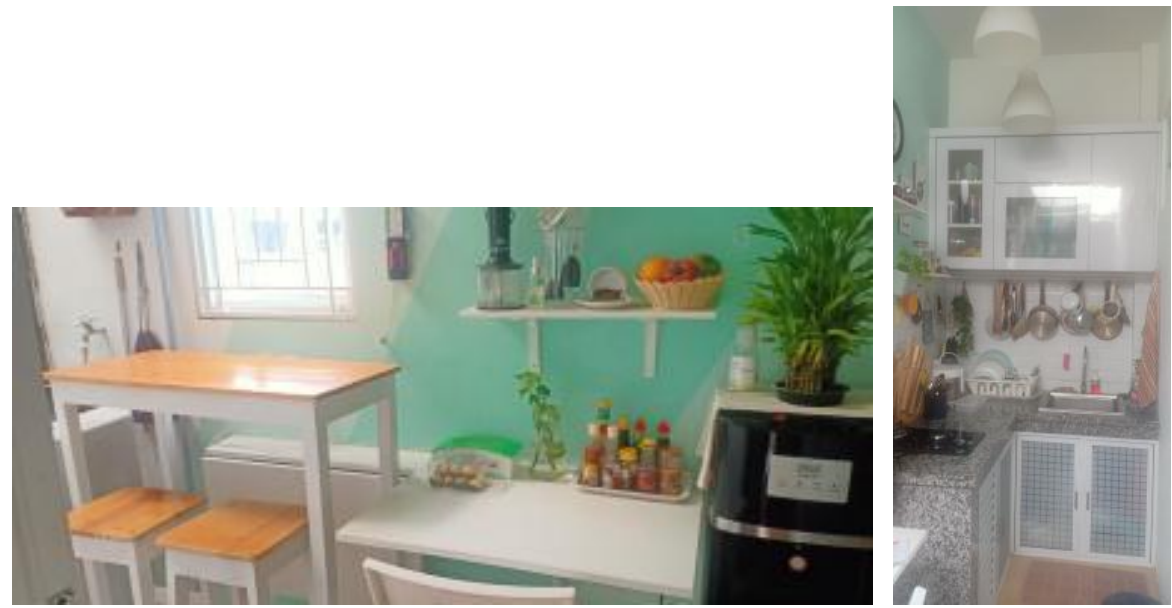

Gambar. 7

Kondisi Pencahayaan Alami pada Ruang Makan dan Dapur pada Kondisi Eksisting

Sumber: Dokumentasi, Desember 2020, pukul 12.00 WIB

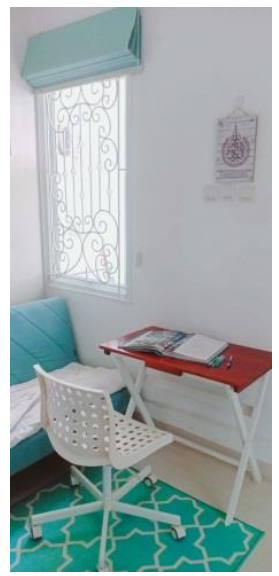

Gambar. 8

Kondisi Pencahayaan Alami pada Ruang Kerja pada Kondisi Eksisting

Sumber: Dokumentasi, Desember 2020, pukul 12.00 WIB

PAWON: Jurnal Arsitektur, Nomor 01 Volume V, Januari-Juni Tahun 2021, ISSN 2597-7636 


\subsection{SOLUSI 1}

Pada kondisi eksisting cenderung terlalu terang pada area skylight dan area dekat jendela. Oleh karena itu perlu ada penggantian material pada skylight dan pembayangan pada jendela. Ada 2 solusi untuk menyelesaikan permasalahan tersebut (Tabel 2). Solusi pertama dengan mengurangi luas skylight sebesar $50 \%$. Jadi $50 \%$ dari skylight tersebut diganti menjadi dag beton. Jendela belakang ditutup korden $100 \%$ dan pada bagian atas jendela belakang diberi horizontal overhang dengan panjang $75 \mathrm{~cm}$ dan lebar $80 \mathrm{~cm}$ (Gambar 9). Jendela ruang kerja dan ruang tidur ditutup korden $50 \%$ untuk mengurangi cahaya masuk ke dalam ruangan. Hasilnya menunjukkan pengurangan lux pada area skylight dan area sekitar jendela (Gambar 10).

Pada ruang kerja, ruang tidur 1 , dan ruang makan mengalami penurunan lux sehingga mendekati SNI (Tabel 3). Perbaikan pencahayaan alami yang paling baik adalah pencahayaan alami pada ruang kerja dan ruang makan. Bahkan pada ruang kerja hanya selisih 10 Lux jika dibandingkan dengan SNI. Pada ruang makan juga terjadi pengurangan Lux dari 1432 Lux menjadi 493 Lux (Tabel 1 dan Tabel 3). Namun, akibat penutupan korden dan pemberian horizontal overhang serta pengurangan luasan skylight menyebabkan daylighting level pada dapur menjadi semakin berkurang nilainya sehingga semakin menjauhi nilai SNI. Oleh karena itu perlu memperbesar masuknya sumber cahaya saat berlangsung kegiatan memasak.

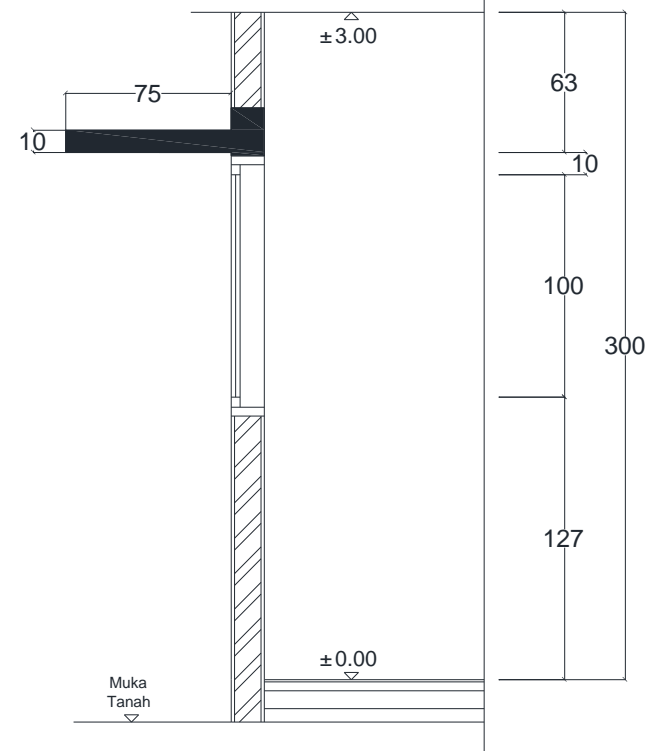

Gambar. 9

Potongan Jendela Belakang (Scale to Fit) Sumber: Ecotect, Desember 2020 


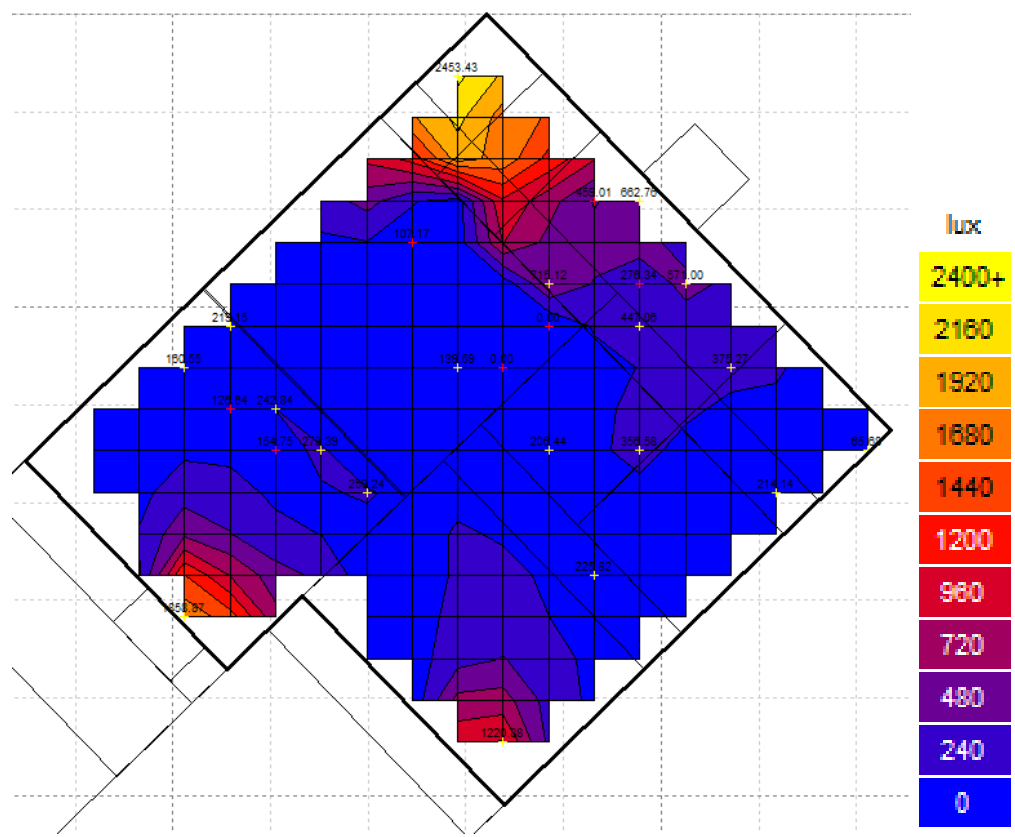

Gambar. 10

Daylighting Level pada Solusi 1

Sumber: Ecotect, Desember 2020, pukul 12.00 WIB

Tabel 2.

Eksperimen dengan Ecotect

\begin{tabular}{|c|c|c|c|c|c|}
\hline & $\begin{array}{c}\text { Jendela } \\
\text { Ruang Kerja }\end{array}$ & $\begin{array}{c}\text { Jendela } \\
\text { Ruang Tidur } \\
1 \\
\end{array}$ & Jendela Belakang & Skylight & $\begin{array}{c}\text { Pintu Ruang } \\
\text { Kerja (Pintu } \\
\text { Depan) } \\
\end{array}$ \\
\hline Eksisting & $\begin{array}{l}\text { Daun jendela } \\
\text { ditutup \& } \\
\text { Korden } \\
\text { dibuka } 100 \% \\
\end{array}$ & $\begin{array}{l}\text { Daun jendela } \\
\text { ditutup \& } \\
\text { Korden } \\
\text { dibuka } 100 \% \\
\end{array}$ & $\begin{array}{c}\text { Daun jendela } \\
\text { ditutup \& Korden } \\
\text { dibuka } 100 \%\end{array}$ & $\begin{array}{l}\text { Luas } \\
\text { Skylight } \\
100 \%\end{array}$ & Ditutup \\
\hline $\begin{array}{l}\text { Solusi } 1 \\
\text { (Kegiatan } \\
\text { Kerja dan } \\
\text { Makan) }\end{array}$ & $\begin{array}{l}\text { Daun jendela } \\
\text { ditutup \& } \\
\text { Korden } \\
\text { ditutup 50\% }\end{array}$ & $\begin{array}{l}\text { Daun jendela } \\
\text { ditutup \& } \\
\text { Korden } \\
\text { ditutup 50\% }\end{array}$ & $\begin{array}{c}\text { Daun jendela } \\
\text { ditutup \& Korden } \\
\text { ditutup 100\%; } \\
\text { penambahan } \\
\text { horizontal overhang }\end{array}$ & $\begin{array}{c}\text { Luas } \\
\text { Skylight } \\
\text { dikurangi } \\
50 \%\end{array}$ & Ditutup \\
\hline $\begin{array}{l}\text { Solusi } 2 \\
\text { (Kegiatan } \\
\text { memasak) }\end{array}$ & $\begin{array}{l}\text { Daun jendela } \\
\text { ditutup \& } \\
\text { Korden } \\
\text { ditutup 50\% }\end{array}$ & $\begin{array}{l}\text { Daun jendela } \\
\text { ditutup \& } \\
\text { Korden } \\
\text { ditutup 50\% }\end{array}$ & $\begin{array}{c}\text { Daun jendela } \\
\text { dibuka \& Korden } \\
\text { Dibuka 100\%; } \\
\text { penambahan } \\
\text { horizontal overhang }\end{array}$ & $\begin{array}{c}\text { Luas } \\
\text { Skylight } \\
\text { dikurangi } \\
50 \%\end{array}$ & Dibuka \\
\hline
\end{tabular}

Daylighting level di area dimana meja belajar berada adalah 209, 339, 526, dan 155 Lux (Gambar 11). Jika keempat titik tersebut dirata-rata maka 
nilainya menjadi 307 Lux. Nilai tersebut mendekati 300 Lux yang merupakan standard SNI untuk ruang kerja.

Tabel 3.

Nilai Daylighting Level (Lux) pada Solusi 1 (Kegiatan Bekerja \& Makan)

\begin{tabular}{|l|c|c|c|c|c|}
\hline & Skylight & Ruang Kerja & $\begin{array}{c}\text { Ruang Tidur } \\
\mathbf{1}\end{array}$ & $\begin{array}{c}\text { Ruang } \\
\text { Makan }\end{array}$ & Dapur \\
\hline Daylighting Level Minimal & 1339 & 127 & 90 & 252 & 0 \\
\hline Daylighting Level Maksimal & 2570 & 1784 & 2464 & 712 & 317 \\
\hline Daylighting Level Rata-rata & 1762 & $\mathbf{3 1 0}$ & $\mathbf{3 7 0}$ & $\mathbf{4 9 3}$ & $\mathbf{1 2 7}$ \\
\hline Nilai SNI 6197:2011 & - & $\mathbf{3 0 0}$ & $\mathbf{2 5 0}$ & $\mathbf{2 5 0}$ & $\mathbf{2 5 0}$ \\
\hline $\begin{array}{l}\text { Selisih Daylighting Level } \\
\text { Rata-rata dengan SNI } \\
\text { 6197:2011 }\end{array}$ & - & 10 & 120 & $\mathbf{2 4 3}$ & $\mathbf{1 2 3}$ \\
\hline
\end{tabular}

Sumber: Ecotect, Desember 2020, pukul 12.00 WIB

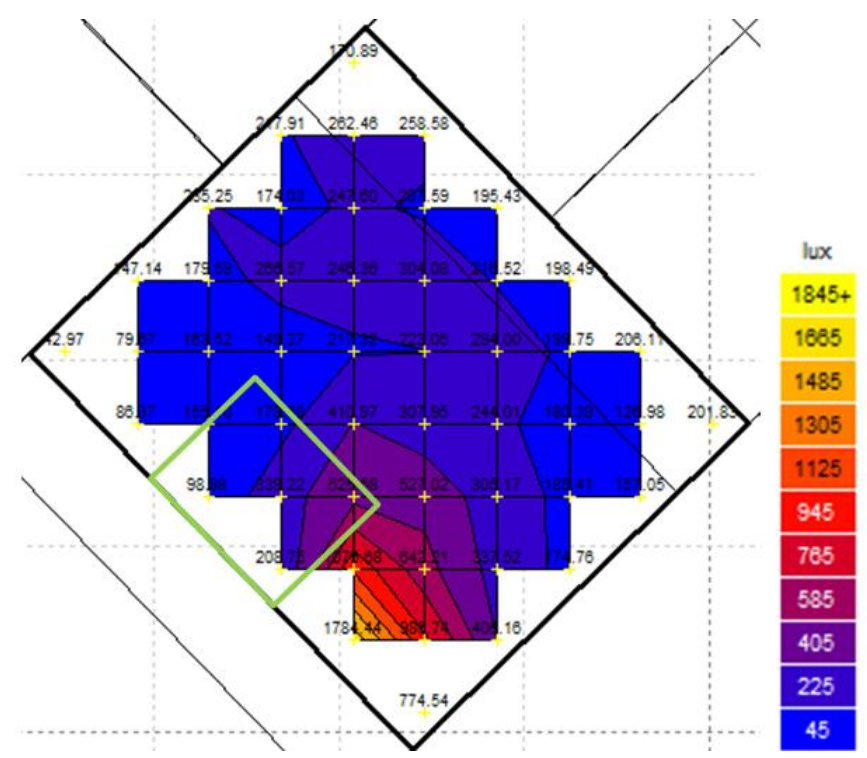




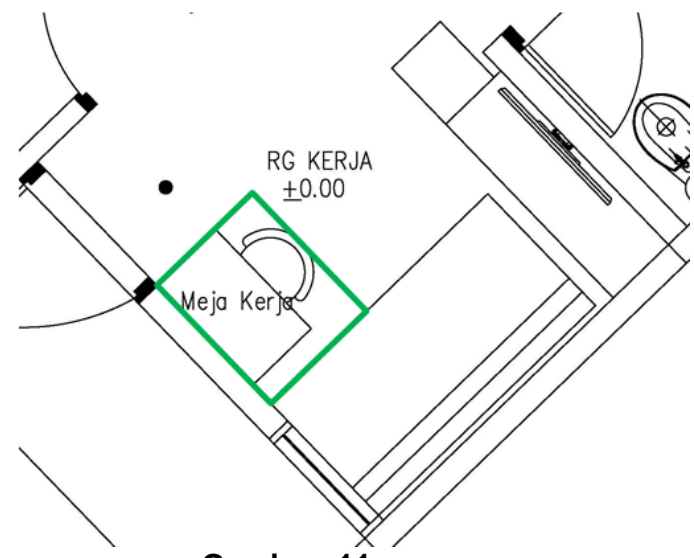

Gambar. 11

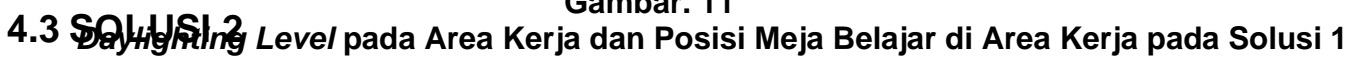
Solusi keđumbor: Elifotect Desember 2020 pukul 12.00 WIB kegiatan memasak, daun jendela belakang dibuka dan pintu ruang kerja juga dibuka (Gambar 12). Dengan dibukanya daun pintu dan jendela tersebut dapat meningkatkan sirkulasi udara sehingga asap dan panas dari dapur bisa keluar. Hasilnya menunjukkan bahwa nilai daylighting level rata-rata dapur pada saat pintu depan dan jendela belakang dibuka adalah sebesar 217 Lux (Tabel 4). Nilai tersebut hampir mendekati SNI untuk dapur yang nilainya 250 Lux.

Tabel 4.

Nilai Daylighting Level (Lux) pada Solusi 2 (Kegiatan Memasak)

\begin{tabular}{|l|c|c|c|c|c|}
\hline & Skylight & Ruang Kerja & $\begin{array}{c}\text { Ruang Tidur } \\
\mathbf{1}\end{array}$ & $\begin{array}{c}\text { Ruang } \\
\text { Makan }\end{array}$ & Dapur \\
\hline Daylighting Level Minimal & 1570 & 398 & 90 & 696 & 56 \\
\hline Daylighting Level Maksimal & 2576 & 4182 & 2469 & 1739 & 621 \\
\hline Daylighting Level Rata-rata & $\mathbf{1 8 4 7}$ & $\mathbf{9 4 6}$ & $\mathbf{4 0 4}$ & $\mathbf{9 6 4}$ & $\mathbf{2 1 7}$ \\
\hline Nilai SNI 6197:2011 & - & $\mathbf{3 0 0}$ & $\mathbf{2 5 0}$ & $\mathbf{2 5 0}$ & $\mathbf{2 5 0}$ \\
\hline $\begin{array}{l}\text { Selisih Daylighting Level Rata- } \\
\text { rata dengan SNI 6197:2011 }\end{array}$ & - & $\mathbf{6 4 6}$ & $\mathbf{1 5 4}$ & $\mathbf{7 1 4}$ & $\mathbf{3 3}$ \\
\hline
\end{tabular}

Sumber: Ecotect, Desember 2020, pukul 12.00 WIB 
Gambar 13 menunjukkan distribusi cahaya pada area dapur. Pada area kompor dan kitchen sink cenderung terang. Area yang kurang terang pada bagian pojok-pojok dinding tapi masih bisa ditoleransi karena pada area tersebut adalah tempat dimana diletakkannya peralatan memasak.

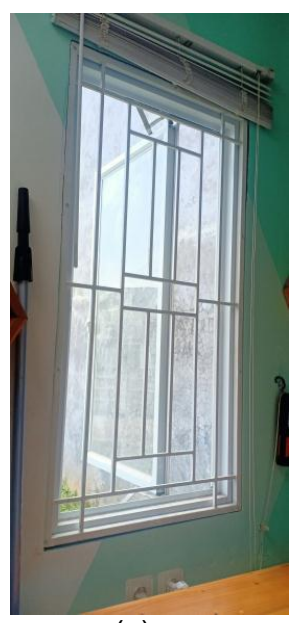

(a)

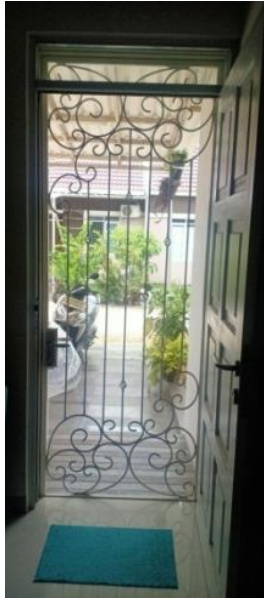

(b)

Gambar. 12

a) Daun Jendela Belakang Dibuka; (b) Pintu Ruang Kerja Dibuka pada Saat Kegiatan Memasak

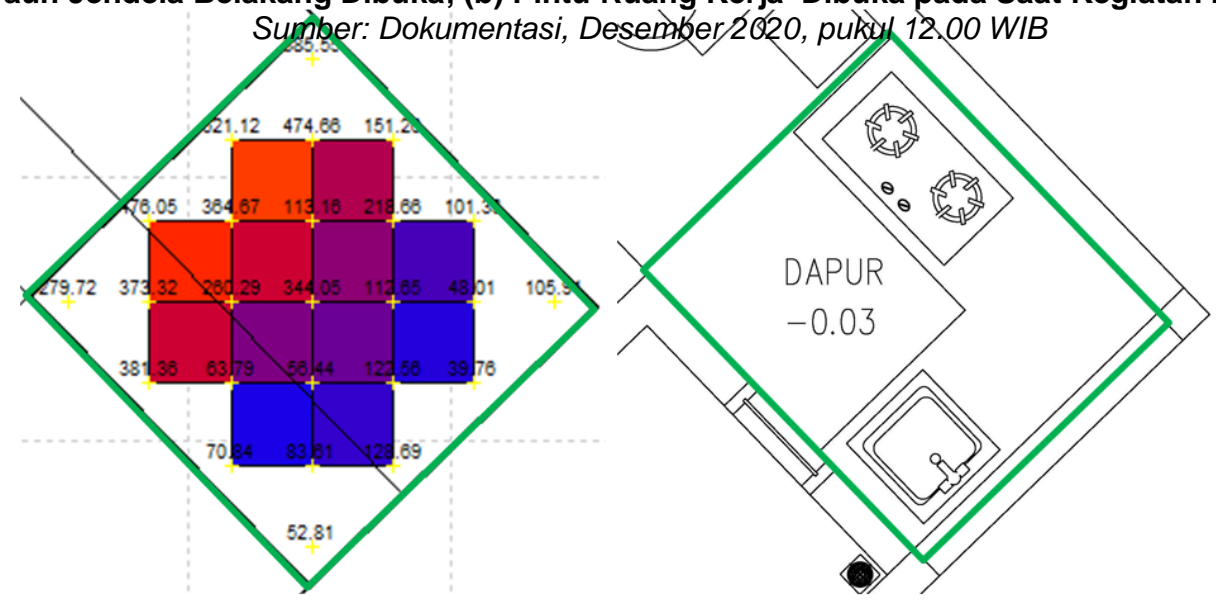

Gambar. 13

Daylighting Level Dapur pada Solusi 2

Sumber: Ecotect, Desember 2020, pukul 12.00 WIB

\section{KESIMPULAN DAN SARAN}

Pengaturan luasan skylight, penggunaan korden, dan pemberian horizontal overhang pada jendela mampu mengoptimalkan pencahayaan

PAWON: Jurnal Arsitektur, Nomor 01 Volume V, Januari-Juni Tahun 2021, ISSN 2597-7636 
alami pada rumah tinggal. Pada sampel penelitian yang diuji, adanya skylight dengan luas $2,7 \mathrm{~m}^{2}$ pada area belakang rumah menyebabkan ruang makan menjadi terlalu terang.

Ada 2 solusi yang direkomendasikan untuk diaplikasikan agar ruang kerja, ruang makan, dan dapur mendekati nilai SNI 6197:2011. Solusi pertama diterapkan pada saat kegiatan kerja dan makan sedangkan solusi kedua diterapkan pada saat kegiatan memasak. Solusi yang pertama dengan menutup korden sebesar $50 \%$ pada jendela ruang kerja dan ruang tidur depan, menutup korden sebesar $100 \%$ pada jendela belakang, pemberian horizontal overhang pada jendela belakang, dan mengurangi luas skylight sebesar $50 \%$. Solusi pertama mampu mengurangi nilai Lux pada ruang kerja sehingga hampir mendekati nilai SNI (selisih 10 Lux). Solusi yang kedua dengan membuka daun pintu depan dan daun jendela belakang. Solusi kedua mampu meningkatkan nilai Lux pada dapur sehingga mendekati nilai SNI (selisih 33 Lux).

Material transparan yang digunakan pada skylight yang tersedia di pasaran, seperti: kaca bening, kaca film, polycarbonat, acrylic, dsb. Ukuran luasan skylight mempengaruhi seberapa banyak cahaya yang masuk ke dalam bangunan. Saran penelitian selanjutnya dapat menguji coba berbagai material transparan dan luasan skylight dengan menggunakan Ecotect untuk mengetahui seberapa besar pengaruhnya terhadap daylighting level pada rumah tinggal.

\section{DAFTAR PUSTAKA}

Atthaillah, Bakhtiar, dan Badriana. (2019), "Optimalisasi Pencahayaan Alami dengan Useful Daylight Illuminance pada Desain Rumah Toko (Ruko) di Kota Lhokseumawe", Jurnal Nature, Volume 6, Nomor 1, Hal 11-26.

Groat, Linda dan David, Wang, (2002), "Architectural Research Methods", Edisi kedua, John Wiley \& Sons, Inc., United States of America

Hartono,T.C dan Kristanto Luciana. (2019), "Studi Efektivitas Pencahayaan Atrium Lenmarc Mall di Surabaya", Jurnal eDimensi Arsitektur, Volume VII, Nomor 1, Hal 601-608.

Ibayasid, Jepriani,S., Musthafa,H., dan Hakim,B.R. (2020), "Pemanfaatan Pencahayaan Alami pada Renovasi Rumah Tinggal Menghadap Arah Barat", Jurnal Politeknologi, Volume 19, Nomor 1, Hal 99-106.

Sabtalistia, Y.A. (2017), "Optimalisasi Pencahayaan Alami dengan Alat Pembayang Matahari (Shading Device) pada Jendela Ruangan Kelas", Jurnal Muara Sains, Teknologi, Kedokteran, dan IImu Kesehatan, Volume 1, Nomor 1, Hal 196-203. 
SNI 6197.(2011). Konservasi Energi pada Sistem Pencahayaan. Badan Standardisasi Nasional. Jakarta. 